\title{
Teaching in the Age of Covid-19 - A Longitudinal Study
}

\author{
Petar Jandrić $^{1,4} \cdot$ Aras Bozkurt $^{2}$ (D) Miranda McKee $^{3} \cdot$ Sarah Hayes $^{4}$ (D)
}

Accepted: 2 August 2021 / Published online: 19 August 2021

(c) The Author(s), under exclusive licence to Springer Nature Switzerland AG 2021

\begin{abstract}
This article presents a longitudinal study of global teaching and learning experiences during the Covid-19 pandemic. The study is based on material presented in two articles written 1 year apart from each other by a group of 84 authors from 20 countries. The first article, 'Teaching in the Age of Covid-19', consists of short testimonies and workspace photographs collected between 18 March and 5 May 2020. The second article, 'Teaching in the Age of Covid-19 - One Year Later', consists of short testimonies and workspace photographs collected between 17 March and 31 May 2021. This material is analysed in several different ways. Some parts of the paper treat the testimonies as personal, positional, narratives, while other parts of the paper examine the testimonies for what they represent as data. Readers are invited to read the original testimonies, view the original images and move back and forth between both narratives and data. As narratives, each author has demonstrated their individual postdigital positionality through praxis. As data, these mutually constitutive accounts offer a much larger, powerful commentary, on the position of educators across the globe during this pandemic. The discussion and conclusion blend the two understandings into a postdigital data-narrato-logy, where data and narrative interact in ways similar to interactions between theory and practice within the concept of praxis.
\end{abstract}

Keywords Covid-19 · Pandemic $\cdot$ Longitudinal study $\cdot$ Postdigital $\cdot$ Positionality · Education $\cdot$ Theory $\cdot$ Practice $\cdot$ Data-narrato-logy

\section{Theory as Anti-Pandemic Practice}

During her keynote address at the Feminism in the 1990s: Bridging the Gap between Theory and Practice Conference, bel hooks recalled her youth in a traditional family of seven children. Speaking in a time and situation very remote

Petar Jandrić

pjandric@tvz.hr

Extended author information available on the last page of the article 
from today's, about her feelings experienced in an even more remote time and context, hooks said:

I came to theory because I was hurting - the pain within me was so intense that

I could not go on living. I came to theory desperate, wanting to comprehend to grasp what was happening around and within me. Most importantly, I wanted to make the hurt go away. I saw in theory then a location for healing. (hooks 1991: 1)

The postdigital world of today has little in common with the post-Second World War world of hooks' childhood. Yet the need to comprehend and grasp the world around us, and the healing powers of knowledge and understanding, are universal - in hooks' words, theory is indeed a location for liberation and healing. Certainly, even the best intentioned theory is useless unless it translates to practice. This is why the critical pedagogy movement, together with its siblings such as anticolonial movements, gender rights movements and many others, has always insisted on the centrality of praxis.

In 2020, the Covid-19 pandemic took the world by surprise, and many people's reaction to the new deadly virus has been one of shock and panic. We soon started to realize that the virus is a 'medical, social, racial, and political problem. Add an adjective of your choice-educational, artistic, whatever-and you cannot go wrong.' (Jandrić 2020a: 535) As we learned more about the virus, shock and panic have slowly morphed into more measured responses. Indeed, anti-pandemic measures are a prime example of the inseparability between theory and practice. As medical researchers publish their preliminary theories about the pandemic, politicians all over the world develop various practical responses for their own contexts. With frightening emergency, anti-pandemic policies turn into very tangible numbers of the infected, recovered and deceased, that feed back into the production of theory. In the pandemic context, theory is literally a location for the healing, or making sick, of large swaths of the global population. Therefore, this section's title needs to be taken literally: theory is indeed anti-pandemic practice.

The philosophical ideal of praxis is a chicken and egg problem, in which neither practice nor theory can claim primacy. This is because praxis relates to the enactment, embodiment or realisation of a practice or theory, where positionality and context bring into play multiple intersecting factors relating to people's identities, roles, power and experience (Acevedo et al. 2015: 39; Hayes 2021a). Whilst real life is often remote from philosophical ideals, the Covid-19 pandemic has a clearly identifiable starting point - the first case of the coronavirus disease was officially reported from Wuhan, China, on 31 December 2019 (World Health Organization 2021). As the world switched to remote emergency teaching and learning (Hodges et al. 2020), the Postdigital Science and Education community collected global individual experiences of teaching and learning in the early days of the Covid-19 pandemic. One year later, we asked the same people about their deeply positional experiences in the 'new normal'. Now, 19 months into the pandemic, the time has arrived for us to translate these practical, contextual 
experiences into theory - as a location for healing and liberation, and as an input into our future practices and policies.

\section{Teaching in the Age of Covid-19}

On 17 March 2020, Petar Jandrić launched a call for testimonies which invited 'teachers at all levels, researchers, academics' to describe how they 'experience this shift in the moment here and now' (Jandrić et al. 2020: 1072). Pointing out that ' $\mathrm{t}] \mathrm{his}$ is not an academic exercise, although you can freely share your academic insights if you feel like sharing them', Jandrić invited anyone on the Postdigital Science and Education mailing list to offer their 'real-time testimonies about challenges, and issues, you are experiencing as your academic work suddenly moves online'. With invaluable input from co-editor Sarah Hayes, this raw material resulted in the collective article, 'Teaching in the Age of Covid-19', which consists of

81 textual testimonies and 80 workspace photographs submitted by 84 authors from 19 countries: USA (13), UK (11), China (9), India (7), Australia (7), New Zealand (7), Denmark (6), Sweden (6), Croatia (5), Canada (2), Spain (2), Nigeria (2), Finland (2), Ireland (2), Malta (1), Tanzania (1), Malaysia (1), Latvia (1), and South Africa (1). (Jandrić et al. 2020: 1070)

One year later, on 17 March 2021, Jandrić and Hayes repeated the call for testimonies and invited all contributors to Teaching in the Age of Covid-19 (Jandrić et al. 2020) to share their 1-year-later experiences. Ninety-two per cent of authors responded to the call, gathered in a collection entitled 'Teaching in the Age of Covid19 - One Year Later' (Jandrić et al. 2021) which consists of

74 textual testimonies and 76 workspace photographs submitted by 77 authors from 20 countries: USA (14), UK (7), China (3), India (7), Australia (6), New Zealand (8), Denmark (5), Sweden (6), Croatia (3), Canada (4), Spain (2), Nigeria (1), Finland (2), Ireland (2), Malta (1), Tanzania (2), Malaysia (1), Latvia (1), South Africa (1), and Germany (1). (Jandrić et al. 2021)

Details about both collections, together with the exact wording of calls for papers, contributor statistics, and so on, can be found in 'Teaching in the Age of Covid-19' (Jandrić et al. 2020) and 'Teaching in the Age of Covid-19- One Year Later' (Jandrić et al. 2021). We also outlined our initial ideas about using the 2020 collection in a dedicated editorial, 'Writing the History of the Present' (Jandrić and Hayes 2020a) and explored its various aspects across a range of publications (Jandrić 2020a, b, c, d; Peters et al. 2020; Hayes, 2021a). Now that both collections are available for analysis, this sustained research effort can be expanded further. In this article, we offer one of the first, if not the first, longitudinal study of global teaching and learning experiences during the Covid-19 pandemic. 


\section{Methodology}

Since the very beginning of collecting these testimonies, we have been fully aware that they can be read in two radically different and incommensurable ways. The first approach is to 'read the testimonies and images as standalone authored pieces'; the second approach is to transform 'our understanding of the material from authored works into data' (Jandrić and Hayes 2020a: 1064). Following our recent research into epistemic and political problems associated with the tendency of contemporary educational research to focus predominantly on data, ${ }^{1}$ we have been cautious about reading this material as data. Yet looking at theory, we found solace in Fawns, Aitken and Jones (2020: 65) argument 'that datafied practices can complement expert judgement when situated within a trusting, formative environment, and informed by an understanding of both pedagogy and technology, and clarity of educational purpose'. Recent developments in postdigital methodologies, which strongly argue for the necessity of inter-, multi-, trans- and even anti-disciplinarity and mixed-methods research (see Jandrić and Hayes 2020b), have contributed to our final decision to treat the testimonies both as narratives and as data. By taking this sensitive and plural approach towards our analysis, we have sought to extend dialogue about the testimonies, rather than risk authors' feeling they have simply been 'datafied'.

Some parts of this paper, therefore, treat the testimonies as personal, positional, narratives and other parts of this paper examine the testimonies for what they represent as data. Our discussion, and conclusion, will blend the two understandings and will reveal too why we think this approach is important, to disrupt more dominant, political generalisations about Covid-19 experiences. As they progress through this article, readers are invited to read the original testimonies, view the original images and move back and forth between both narratives and data. Our postdigital methodology is data-narrato-logy, in which data and narrative interact in ways similar to interactions between theory and practice within the concept of praxis. Without further theoretical ado, we can only hope that such a relationship will have similar liberatory and healing effects for the authors of the testimonies and for society at large.

Text and image, image and text, are another curious couple: always together, never quite finding a common language. Certainly, visual pedagogies are today an established field of inquiry; experts in various fields, from art history to data science, have devised more ways for reading images than are humanly comprehensible. Therefore, Petar Jandrić and Sarah Hayes invited two co-authors: Aras Bozkurt, who took up the textual analysis, and Miranda McKee, who took up the image analysis. Petar wrote the introduction, background and methodology; Sarah wrote the discussion and conclusion, and all four of us freely wrote into each other's parts, in a participatory and dialogic process of praxis in itself, which Sarah comments further on, in the concluding sections.

\footnotetext{
1 See Special Issue of Postdigital Science and Education, "Measuring Excellence" in Higher Education', edited by Sarah Hayes, at https://link.springer.com/journal/42438/volumes-and-issues/3-1. Accessed 15 July 2021.
} 
Since its inception, the Postdigital Science and Education community has been keenly interested in postdigital dialogue and its epistemic implications (see Jandrić et al. 2019; Arndt et al. 2019; Traxler et al. 2021). Whilst dialogue takes place amongst co-authors as they co-construct an analysis, this is not always a discourse that is explicit for readers to consider. In our approach, we try to share this dialogic dimension. Indeed, inviting two co-authors we have never met in person, based on their works, but hardly knowing what they are like to work with, is a very postdigital beginning for a postdigital dialogue. Yet, more importantly, this paper is a result, and a starting point of, a dialogue between 84 authors from all over the world, and then also a result, and a starting point of, a dialogue between two temporal incarnations of each and every one of us. Everyone who has heard themselves talking on YouTube knows the uncanny feeling of listening to one's own voice, and we freely admit that reading our own words written at the same date last year was a similar, not entirely pleasant experience. On 17 April 2020, I felt that showing my untidy (home) desk was 'authentic'; on 17 April 2021, I timidly tidied up my (work) desk before taking a photo. When she said that theorizing our efforts will be liberatory and healing, hooks forgot to say that those processes are far from comfortable. Thus, it is worth considering how the levels of engagement or discomfort experienced by each author may have varied individually, as well as drawing more collective observations from what we notice in their narratives as data.

Liberation and healing are deeply personal. For me, Petar, this paper has achieved its purpose even if no-one ever reads it - similarly to hooks, these practical testimonies would haunt me forever had we not theorized them. If this paper achieves a similar effect in just a few more people, our effort is already justified. However, individual emancipation and healing is dialectically intertwined with others - the authors of the testimonies, and the co-authors of this piece. We all wrote this paper together, and its conclusions touch each of us in different ways. Theorizing our practical experiences of the pandemic, this paper offers important signposts for future practices, which we, or indeed someone else, will need to theorize again. For better or worse, this article is just a small step in the eternal play between theory and practice.

By introducing the concept of play, I reach my last point for this section. A few years back, I wrote an editorial entitled 'We-Think, We-Learn, We-Act: The Trialectic of Postdigital Collective Intelligence' (Jandrić 2019). I cannot recall how, or why, I arrived at this 'brilliant' idea to write about collective intelligence on my own. Yet when the deed was done, I started receiving emails saying that I forgot to even mention feelings, and I immediately realized the stupidity and arrogance of my actions (thank you, reviewers!). Soon after, Sarah and I added the concept of we-feel (Jandrić and Hayes 2020b), and for now, the critiques have settled down. Shamed by my own arrogance, I unconsciously followed hooks' (1991) footsteps and sought solace in theory.

All knowledge is socially constructed. Writing alone about collective intelligence, and forgetting something as important as feelings, is indeed not a very intelligent move. But perhaps, and I will never know whether this is true or false, my obviously incomplete article on we-think, we-learn and we-act was a necessary step 
towards revealing the importance of we-feel - for me, and also for the community who reacted to my article. A similar line of argument applies to this longitudinal analysis of Covid-19 testimonies. Written directly by 4 authors, and indirectly by 84 more authors, this paper is just one step towards our collective making sense of our historical moment. Based on a limited number of participants, from a limited number of countries, this article probably does not offer potentials for a major theoretical breakthrough. Yet, I hope that it may heal, emancipate and provide the necessary impetus for another round of the eternal spin between theory and practice.

\section{Textual Analysis}

Textual analysis consists of data mining and analytic approaches (Fayyad et al. 2002) such as t-distributed stochastic neighbour embedding (t-SNE) (van der Maaten and Hinton 2008) and text mining (Feldman and Sanger 2007). T-SNE visualize 'high-dimensional data by giving each datapoint [words in the examined articles] a location in a two or three-dimensional map' (van der Maaten and Hinton 2008: 2579). Text mining through lexial analysis provides 'two stages of co-occurrence information extraction—semantic and relational—using a different algorithm for each stage' (Smith and Humphreys 2006: 262). The rationale for using two types of approaches by triangulation (Thurmond 2001) is to gain a multidimensional perspective, explore the different layers of the data and increase the validity and reliability of findings.

The t-SNE analysis is an unsupervised 'nonlinear dimensionality reduction technique that aims to preserve the local structure of data' (van der Maaten and Hinton 2008: 2580) and is used to explore the focal point of a sheer volume of textual data. In this analysis procedure, the two papers were examined after excluding the metadata (e.g. references, author bios, etc.). The first document, Jandrić et al. (2020), includes 49,529 total words and 6586 unique word forms (meaning that these were used only once), and the second document, Jandrić et al. (2021), consists of 41,819 total words and 5935 unique word forms. Text-mining identifies lexical patterns and visualizes these patterns through thematic concept maps based on the hierarchical order, ray intensity and proximity of the textual data (Smith and Humphreys 2006).

\section{t-SNE Analysis}

This section identifies the focal points of the two articles which provide a longitudinal perspective regarding teaching during the Covid-19 pandemic. The analysis of Jandrić et al.'s (2020) first paper identifies a dominant cluster (see Fig. 1, bottom left) which centres the discourse on online emergency remote teaching. The most frequent nodes in Fig. 1 are online, students, university, covid, teaching, new, learning, education, world, pandemic and research. These appear in an unusual setting (e.g. personal and domestic spaces) which emerge as a relatively separate cluster (see nodes in Fig. 1: work, home, time, social, working, people, face, life and family). 


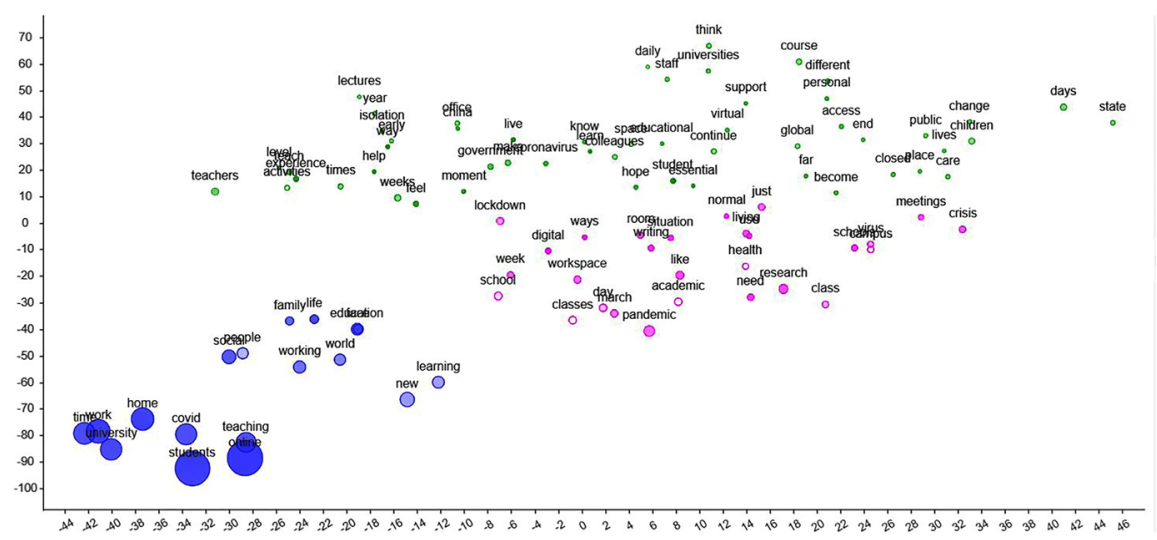

Fig. 1 Scatter plot of the textual data from Jandrić et al. (2020)

The analysis of Jandrić et al.'s (2021) second paper identifies a more dominant and condensed cluster that centres the discourse on online distance education. See nodes on Fig. 2: year, students, pandemic, online, new, covid, teaching, time, home, university and work. We see that teaching and working at home emerge as a part of the dominant cluster. The t-SNE analysis indicates that instructors' concern of ensuring and enabling emergency remote online teaching practices in personal or domestic spaces during the first waves of the Covid-19 pandemic later shifted focus onto providing online distance education.

Emergency remote teaching (ERT) is different from online distance education (ODE) (Hodges et al. 2020; Bozkurt and Sharma 2020a). While ERT is a mandatory practice with all resources available and which is focused on the survival and continuance of education in a time of the crisis, ODE is more about flexible, optional and planned practices that are based on the theoretical and practical pillars of the field

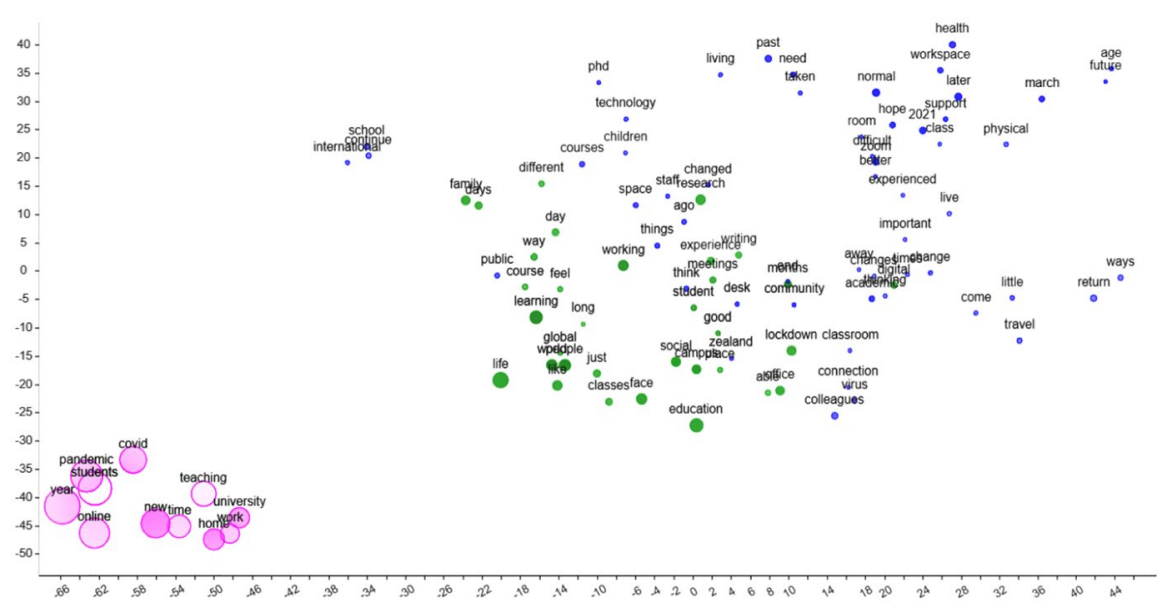

Fig. 2 Scatter plot of the textual data from Jandrić et al. (2021) 
(Bozkurt et al. 2020). The difference between the broad themes of the two studies indicates that teaching practices continued during the pandemic with all resources available including using shared spaces to deliver education. By shifting from room to roam strategy and embracing the flexibility of online distance education (Yusoff et al. 2020), educators reimagined existing educational strategies or (re)invented their own strategies (Mishra et al. 2020). They did this on survival mode by suppressing uncertainty, anxiety and fear-related factors to ensure the sustainability of education in the midst of a critical period (Loose and Ryan 2020). In all, the t-SNE analysis clearly demonstrates that educators swiftly adapted to teaching in the closure and absence of public educational infrastructures and benefited from their personal, and in many times, domestic shared spaces.

\section{Text-Mining Analysis — Jandrić et al. (2020)}

Textual data is composed of words, and words gain ground in the contexts in which they are used.

Direct and indirect lexical relationships formed by words and meta-narratives articulated in sheer volumes of text can be visualized by text mining. This section considers the two articles as textual data sources and analyses them to identify emerging themes to compare and contrast what has changed in teaching during the Covid-19 pandemic. Upon the analysis of Jandrić et al. (2020), three thematic clusters emerged (Fig. 3).

\section{Intermediate (Shared) Workspaces in a Time of Crisis}

See the paths in Fig. 3: workplace, bedroom, workspace, room, living, space, office, home, work, meetings and personal, family, time, connection and lockdown, children, home.

During lockdown, individuals were advised to self-quarantine or forced to stay at home to lessen physical/social contact and, thus, lessen the spread of the Covid-19 pandemic. Spaces of social contact, including educational spaces, were closed down and that led to the need to sustain teaching practices at home. This resulted in blurring borders between professional and personal/family life and further leading to the emergence of intermediate, shared workspaces in homes.

From the perspective of facilitating educational processes, Cahapay (2020) argues that the pandemic forces us to reconceptualize teaching and learning spaces. It is evident that temporal and spatial distances have always been an issue for distance or remote education (Moore and Kearsley 2012), yet, it has always been a transactional distance (Moore 1993) that was vital for effective and efficient teaching and learning. The theory of transactional distance argues that dialogue and structure identify the density of transactional, in other words, psychological and communicational distances. In this regard, it can be argued that rather than where one teaches, but how one lessens transactional distance, matters.

While the focus of this paper is teaching at a distance in personal or shared domestic workspaces, it is worth drawing attention that the case requires 


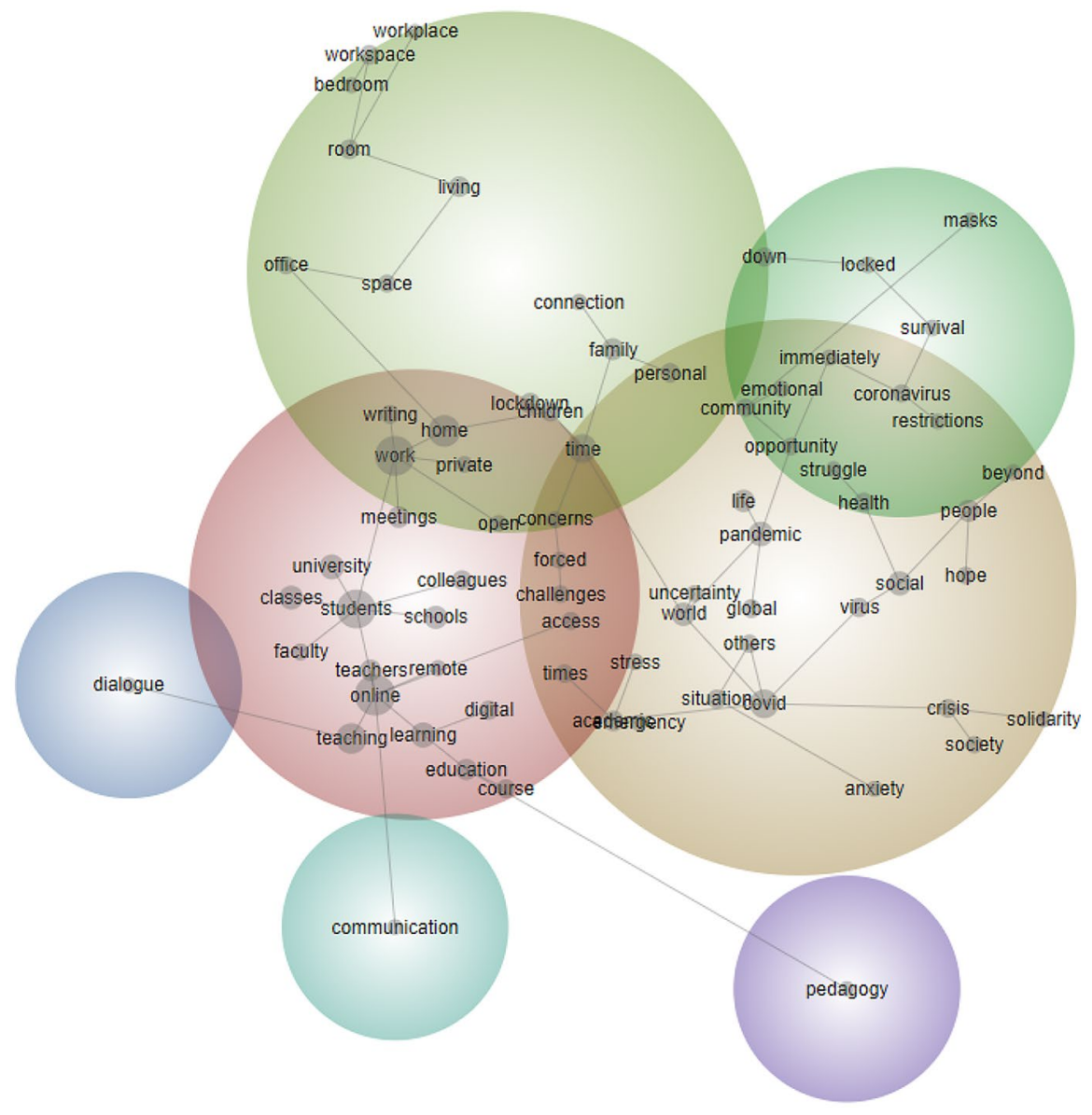

Fig. 3 Text-mining of the textual data from Jandrić et al. (2020)

developing a two-pronged perspective from the angles of teachers and learners. What is alarming might not be that teaching practices were provided in intermediate shared workspaces, but the capabilities of these spaces, and how they relate to the digital divide, equality and equity. Beyond moving teaching practices into homes, we have to query if everyone has the same opportunities and, if not, which kind of inequalities and inequities can emerge? Likewise, how do learners feel on the other side of the screen and which kind of inequalities and inequities are they exposed to and how such issues impact our teaching practices?

\section{The Covid-19 Pandemic is a Social, Psychological, (and Educational) Crisis as Well as a Biological One}

See the paths in Fig. 3: masks, community, emotional, pandemic, life, uncertainty and restrictions, coronavirus, survival, locked, down, and covid, virus, 
social, health, people, hope, and anxiety, situation, others, covid, crisis, society, solidarity.

What the world faced with the advent of the Covid-19 pandemic first seemed and sounded unreal, and many people felt as if they witnessed an imaginary dystopian future with many fictitious circumstances. However, the pandemic was real and taught us how fragile the world is and how helpless we are despite all technological advances.

The impact of the Covid-19 pandemic was comprehensive and, therefore, has been referred to in many ways as a great reset (Time 2021). Referring to transformational changes due to the Covid-19 pandemic, Bozkurt and Sharma (2020b) argue that.

[t]oday we are living in a strange new world, where to be social means to keep distance and, weirdly, to be labelled positive has negative connotations. These developments suggest that we are on the brink of a new future, where time would be understood in terms of $\mathrm{BC}$ and $\mathrm{AC}$, to indicate before and after COVID, respectively. (Bozkurt and Sharma 2020b: i)

Such a view urges us to think deeper about what is normal, and new normal, and what the new norms refer to (Bozkurt and Sharma 2020a, b; Xiao 2021a).

Considering that the Covid-19 pandemic is not merely a biological threat, it has broken the natural flow of life, disrupted the social living of humans and forced them to question their immediate survival. This all understandably leads to mental health issues. In education, it has been reported that the pandemic mentally affects learners which can lead to depression, anxiety, stress and a sense of loneliness (Elmer et al. 2020), and it has been further highlighted that issues rooted in social, psychological and philosophical aspects of the pandemic on the general population will have a 'lasting impact on societies and on particular individuals' (Rudnick 2020: 3 ). The current outlook requires us to acknowledge the pandemic beyond a biological threat, be proactive regarding social and psychological aspects and be prepared for the reflections of multifaceted consequences of the pandemic in the educational landscape.

\section{[Emergency Remote] Online Teaching and Learning as a Survival Reflex}

See the paths in Fig. 3: pedagogy, course, education, digital, learning, online, remote and communication, online, teaching, dialogue and teachers, students, classes, faculty, university, colleges, survival, coronavirus, pedagogy, pandemic and schools, education, learning, online, teaching, classes, dialogue, communication, university, faculty, students, and school, digital, student.

Much has been said regarding what emergency remote teaching and learning is (Bozkurt et al. 2020; Bozkurt and Sharma 2020a; Hodges et al. 2020), but less has been articulated about why and for which purposes we practiced it during the pandemic. The greatest human gift is the ability to think and learn, and this makes us different and stronger in our ecology, and when we are under threat, we 
learn and adapt to survive. Emergency remote teaching and learning was, therefore, a survival reflex, a survival response to the Covid-19 crisis.

To be resilient and agile in the new normal, we had to \#KeepTeaching and \#KeepLearning at all costs (UNESCO 2020), and, in fact, emergency remote online teaching and learning served this purpose perfectly. Despite our pedagogical sins of copying and pasting face-to-face education processes into online distance education (Bozkurt and Sharma 2020b), communication was a pedagogical social glue which worked well during the pandemic times and reminded us how vital it is to socially empower and facilitate teaching and learning.

\section{Text-Mining Analysis — Jandrić et al. (2021)}

The analysis of Jandrić et al. (2021) identifies three other thematic clusters (Fig. 4).

\section{Evolved and Adapted Workspaces in the New Normal}

See paths in Fig. 4: workplace, home, family, living, children, work, academic, university, zoom, meetings and garden, workspace, bedroom, room and adapt, year, moved, changes.

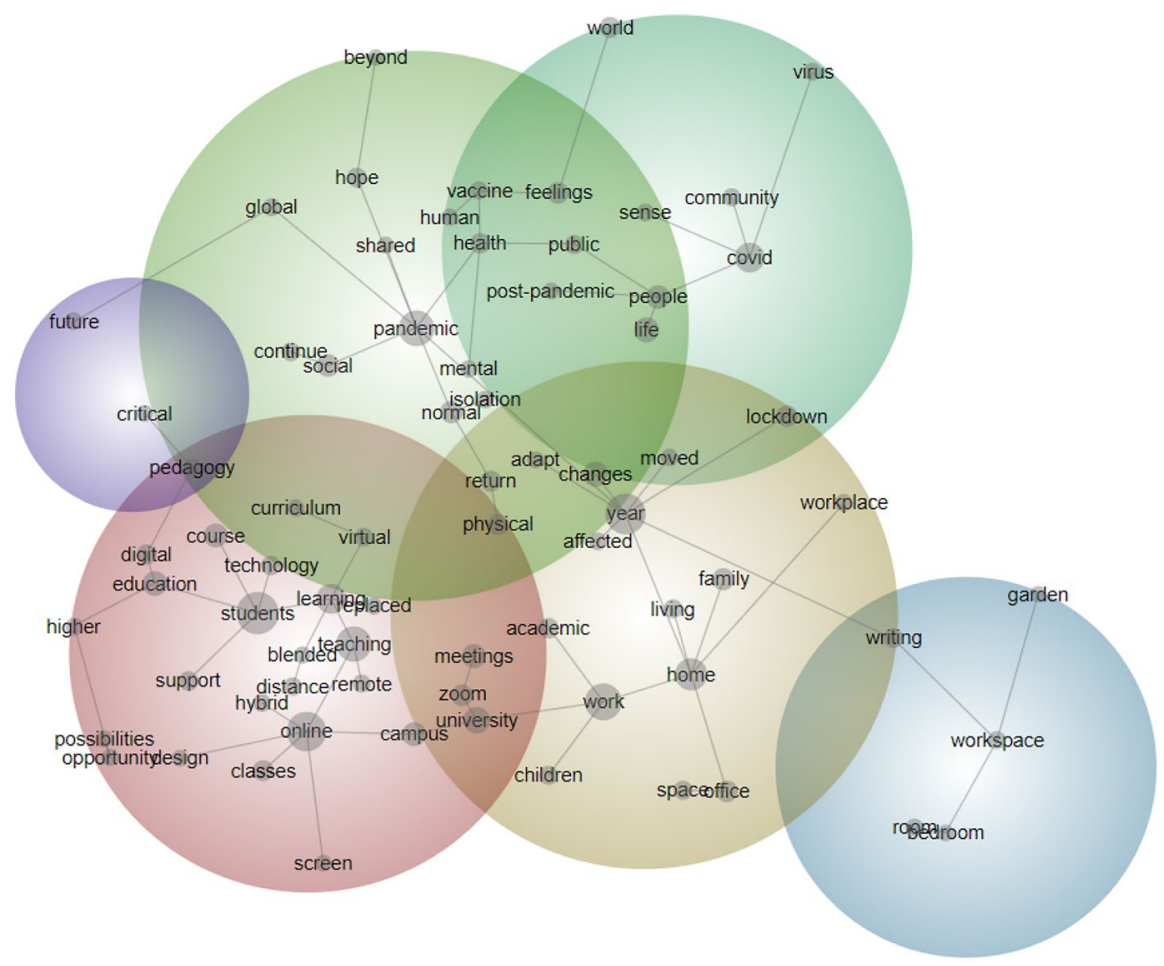

Fig. 4 Text-mining of the textual data from Jandrić et al. (2021) 
The pandemic has been disruptive, but also transformational. The 2020 and 2021 collective reflections demonstrate that we continued teaching in shared but modified workspaces where being and teaching online is part of the new normal. Advocating the idea that suspending education in physical spaces does not mean teaching and learning stops (Zhang et al. 2020), teaching has become a part of daily routines at homes during the pandemic times.

The pandemic not only forced us to evolve and adapt ourselves but also our teaching and learning spaces, and methodologies. This required us to rethink how and where we teach, reconsider what are the key elements and procedures of teaching (Dwivedi et al. 2020), reinvent emerging pedagogical roles of teachers (Darling-Hammond and Hyler 2020) and repurpose pedagogical, social and economical roles of educational institutions in the shifting landscape of education (Bozkurt et al. 2020; Peters et al. 2020). Again, this requires us to rethink what teaching is in the new normal and what are the new norms?

\section{Survival Skills and Human Needs in the New Normal}

See paths in Fig. 4: Future, global, pandemic, normal, return, physical and continue, social, pandemic, health, mental, human, vaccine, feelings, world and public, people, post-pandemic, life, covid, virus, sense, community.

Being social and socially connected are essential [survival] needs, and, in this regard, sustaining communication with social circles is a survival skill. From a Darwinian perspective (Darwin 1859), we will select or be selected to be the fittest to survive (Spencer 1908). During the pandemic, in contrast to Nietzsche's (1986) arguments on hope, against all negative conditions and feelings, people kept hoping to effectively cope with the stress and anxiety because hope 'may lead individuals struggling through the Coronavirus pandemic to look towards the possibilities for the future, rather than the obstacles of the present' (Gallagher et al. 2021: 242). The virus is contagious, and so is hope. The individual and collective density of hope is an indicator of resilience and therefore hope(ing) was also a survival need for educators, societies and all individuals.

\section{A Shift from Online Distance Education to Hybrid/Blended Education}

See paths in Fig. 4: campus, online, classes, screen, design, hybrid and distance, blended, learning, replaced, teaching, remote, curriculum, virtual and critical, pedagogy, education, higher, possibilities, and course, students, technology, support.

Almost 1 year after the start of the Covid-19 pandemic, we metaphorically, like nomads, moved our teaching from campus walls to screen walls. Meanwhile, we learned by experience that we not only need digital tools, but we also need digital literacies and competencies. 
The Covid-19 pandemic was not the first threat to education and will not be the last. We, therefore, need 'a sort of radical flexibility as a way to create life-sustaining education, not just for some, but for all, and not just for now, but far into the future' for the practice of freedom (Veletsianos and Houlden 2020: 849), for accessibility, equity and so much more. While meaningfully adapted educational technology and blended/hybrid educational modes (Pelletier et al. 2021) have the capacity to ensure flexibility, it is also about the care and empathy-oriented critical pedagogy (Bozkurt and Sharma 2021).

Before blindly adopting hybrid/blended education, we have to remember that teaching and learning are human enterprises (Xiao 2021b), and educational design considerations should orbit around human-centred approaches (Karakaya 2021) as teaching and learning are 'primarily about human beings, for human beings and by human beings' (Xiao 2021a: 3). It is evident that we are shifting into a future where, if we fail, there will be consequences (Bozkurt and Sharma 2020b; Costello et al. 2020). Therefore, we need to plan carefully, adapt human-centred pedagogies before being seduced by the temptation of digitally facilitated educational opportunities such as hybrid or blended education.

\section{Image Analysis}

Jandrić reminds us '[a]ll knowledge is socially constructed' (Jandrić et al. 2021), and this sentiment is important to consider when approaching image analysis. Photographs help us to explore and 'know' our world, yet each image is constructed within a particular socio-cultural context (Berger 1972). Far from objective in nature, each photograph is purposefully constructed by its author, determining what is visible or hidden from the frame (Sontag 1990). These decisions, conscious or unconscious, are influenced by the author's beliefs and visual culture. Thus, while the written testimonials provide a first-person account which is shaped by the traditions, affordances and limitations of the written word, the images submitted to Jandrić's open call provide a distinct data set from which we can draw unique insights about the experience of individuals.

To undergo an experience with something-be it a thing, a person, or a godmeans that this something befalls us, strikes us, comes over us, overwhelms and transforms us. When we talk of 'undergoing' an experience, we mean specifically that the experience is not of our own making; to undergo here means that we endure it, suffer it, receive it as it strikes us and submit to it. (Heidegger 1982: 57)

The image-based testimonials provide documentation which speaks to the transformative impact Covid-19 has had on the working lives of educators. Through photographs, participants aimed to visually describe their new professional environment. Some of these documents portray a curated view, while others expose the haste of the transition to working from home, and the challenges faced. While some contributors appear more deliberate with the choices made 
and objects portrayed in the frame, our point of departure here is the assumption of agency. We view each of these images as an act of curation, whether elaborate or simple, permanent or makeshift. Our workspaces can be seen to portray our public lives in an intimate manner, or vice versa. For example, what does a wall full of books on shelves symbolize? What are we not seeing in these images, and why are certain things excluded from view? Through image analysis, these and other questions are considered.

\section{Theoretical Framework and Methodology}

Assuming the theoretical framework of hermeneutic phenomenology (Eddles-Hirsch 2015), the analysis of imagery provides an opportunity to gain insight into the impact of Covid-19 on the working lives of educators. Connecting this framework with image analysis, Davey (2005: 10) explained: 'Far from subordinating image to word, hermeneutical aesthetics is concerned with the sensitive use of words to bring forth what is held in an image.' Following phenomenological practices, we are able to learn more about the essence of a shared experience (Patton 2015) by analysing how participants visually interpreted their environment. Given the nature of our positionality as researchers who, much like the participants, are also experiencing the pandemic while engaging in academic labour, a phenomenological approach is fitting (Eddles-Hirsch 2015). Although we cannot extract ourselves entirely from this phenomenon, as we too are living through a pandemic, nor can we completely bracket the socio-economic, cultural contexts within which we find ourselves (Flood 2010), we can instead acknowledge our positionality and reflect upon this in relation to the content we examine.

The methodology employed here to examine images critically is semiotic in nature. By coding the visual signs and symbols contained within each image with the support of qualitative analysis software, we compare and contrast longitudinally the visual data provided by participants.

\section{Emerging Themes}

In total, 80 image submissions were evaluated from Jandrić et al. (2020) and 76 image submissions from Jandrić et al. (2021). Thirty-three codes tracked visual symbols and signifiers from which we consider the various themes that emerge. In Fig. 5, the instances are referred to by percentage in relation to the whole set, 80 in 2020 and 76 in 2021, which allows for a longitudinal comparison despite a change in the total from 1 year to the next. In the few cases where multiple photos were submitted by one participant, the images were considered one unit together in order to evaluate the data as reflective of the sample size. 


\begin{tabular}{lr|r}
\multicolumn{3}{c}{ Jandrić et al. (2020) } \\
\hline Code & $\%$ of total & $\begin{array}{r}\text { Occurences } \\
\text { (Out of } 80)\end{array}$ \\
\hline no person & $79 \%$ & 63 \\
window/daylight & $64 \%$ & 51 \\
one screen & $63 \%$ & 50 \\
clutter & $60 \%$ & 48 \\
book(s) & $51 \%$ & 41 \\
screen on & $45 \%$ & 36 \\
wide view & $43 \%$ & 34 \\
multipurpose space & $35 \%$ & 28 \\
first person & $35 \%$ & 28 \\
art/music/antiques & $34 \%$ & 27 \\
\hline
\end{tabular}

\begin{tabular}{lr|r}
\multicolumn{3}{c}{ Jandrić et al. (2021) } \\
\cline { 1 - 2 } Code & \% of total & $\begin{array}{r}\text { Occurences } \\
\text { (Out of 76) }\end{array}$ \\
\cline { 1 - 2 } no person & $74 \%$ & 55 \\
one screen & $54 \%$ & 40 \\
book(s) & $49 \%$ & 36 \\
first person & $47 \%$ & 35 \\
window/daylight & $47 \%$ & 35 \\
screen on & $46 \%$ & 28 \\
art/music/antiques & $38 \%$ & 26 \\
no clutter & $35 \%$ & 25 \\
Clutter & $34 \%$ & 25 \\
office chair & $34 \%$ & \\
\hline
\end{tabular}

Fig. 5 Ten most frequent code occurrences based on image analysis

\section{Workspace Upgrades}

The most significant visible changes from the first set of images (Jandrić et al. 2020) to the second set of images (Jandrić et al. 2021) emerge while noting the presence of additional technology and workstation upgrades. As revealed in the text mining analysis, instances of external webcams, external microphones and professional lighting rose from 2 to $18 \%$, indicating participants made investments as they progressed from ERT to ODE (Bozkurt 2021). Similarly, workspaces with multiple screens per user increased from 24 to $31 \%$. The visual evidence of office chairs (identified by visual characteristics such as rolling wheels, adjustable arms or headrests) rose from 26 to $34 \%$, and purposefully curated backgrounds for video calls also increased from 10 to $15 \%$. The instances of photographs displayed anywhere in their working space more than doubled as participants appeared to show an increased interest in curating their visual surroundings 'at work.'

In a few particular instances, the 2020 images lay bare temporary working environments that appeared unsustainable in the long term. For example, two participants sought refuge inside walk-in closets, and three more set up working space on the floor at home in an effort to secure private space away from other household members. Participants portrayed working from couches, beds and sofa chairs, which perhaps offered the initial comforts of home but were short-lived and reduced significantly from $9 \%$ in 2020 to $3 \%$ in 2021 . The 2021 dataset reveals that these shortterm solutions were temporary, and understandably so, as it would have been ergonomically uncomfortable for the long term.

\section{A Curated View}

An increase was also evident in the use of first-person perspective from the 2020 image set at $35 \%$ to the second image set at $47 \%$. This perspective is narrower, replicating what you might see if you were sitting at the workstation, which differs 
from a wide-angle perspective where additional items surrounding the desk would be visible. Instead of stepping back and photographing the whole room, participants zoomed in to provide a viewpoint that mirrored their own line of sight while at work. This tendency to show less as participants transition from 2020 to 2021 is consistent with the tracking of wide-angle views, which initially presented as $43 \%$ of the photos in the first article, and dropped to only $14 \%$ in the second round of testimonials. From these numbers, participants appear to have intentionally reduced the amount of physical space shared in their images from 2020 to 2021.

Not only are we seeing a more narrowed perspective in the 2021 imagery, but what remains within the frame appears to be more purposefully curated. For example, in the 2020 image set, $60 \%$ of the images portrayed what could be described as a cluttered workspace, with items strewn across surfaces in a haphazard manner. As we learned in Jandrić's introduction, an initial sharing of his slightly dishevelled workspace in 2020 intended to reflect a sense of authenticity, an earnest portrayal of the circumstances. One year later, participants appear to have felt the need to present their space, and in turn perhaps themselves, as more 'put together', and we saw instances of cluttered workspaces dropped to 35\%. It has also become clear that many participants were no longer sharing their workspace with other people or activities 1 year into the pandemic. Photographs of rooms that were visibly multipurpose reduced from 35 to $27 \%$, while shared desk space decreased visually from 16 to $11 \%$. The photographic perspective became more focused in 2021 testimonials, and it appears that the work spaces themselves became more singularly focused.

\section{Symbols of Knowledge, Signs of Privilege}

The natural tendency to see printed books as a visual symbol of knowledge is reinforced by studies like that of Sikora et al. (2019: 14), which found a correlation between early exposure to a robust home library and 'life-long cognitive competencies' for children raised with collections of books. While we may practically interpret one book or a small stack on a desk as representative of ongoing work for participants in this study, which was visibly evident in roughly half of the photos in both 2020 and 2021, 25\% of the respondents to the first call for submissions included shelves of books in their photograph. The presence of bookshelves reduced slightly to $20 \%$ in the images submitted in 2021 , which could again be due to the narrowing of the frame. Publications are of course central to academic work, and the pandemic has turned our focus to digital editions, particularly when taking into account student access. Has this subtly influenced what participants have chosen to include in the frame?

From symbols of knowledge, we must also consider signs of privilege within the image analysis. We know from initial studies that Covid-19 has widened the economic divide (Milan 2021). Visual symbols of privilege take multiple forms, and we see these symbols increase from the 2020 image set to the 2021 set. The presence of artworks, musical instruments and antiques within the photographic frame increased from $34 \%$ in the first series to $38 \%$ in the second. Having a window in your working space filtering in daylight or an outdoor space to work in can also signify privilege. 
We see instances of windows/daylight change from 64 to $47 \%$ from the first article to the second. This could be an indication of participants downsizing during the pandemic or merely the narrow frame cropping out evidence of this visual cue.

We must also consider that we are not the only viewers of these spaces. As Bozkurt aptly pointed out in the 'Text Mining Analysis' section, we must consider the gaze of learners who are in many cases peering into the same rooms from the other side of the computer screen. Students are provided with a small window into the personal space of their instructor and similarly must share, or deliberately hide, the setting of their learning-from-home circumstances. Much like the clothes we wear and the words we choose, the environment within which we broadcast ourselves is now providing information about us to the viewer, our wealth or lack of, our symbols of knowledge and privilege and more. Educators now have additional factors to consider in the curation of their workspace. Will this painting inspire my students or alienate them? Should we be using our real/virtual backgrounds as a space for activism? Should these projected spaces be stripped of wealth indicators in order to respect the economic strife that pervades many of the households viewers inhabit?

\section{The Human Element}

The majority of participants in both articles chose not to be physically portrayed within their photographs, which focused instead on their empty workspace. Seventynine per cent of the photographs in Jandrić et al. (2020) and 74\% in Jandrić et al. (2021) show no people at all. Of those participants who included a person within the frame, half of these images portrayed a person 'working', looking at a screen or printed material. The other half acknowledged the audience by looking at the camera, reflecting a traditional portrait composition. While the percentage of participants sharing a traditional portrait remained relatively consistent from 2020 to 2021 at $8 \%$ and $9 \%$, respectively, there was a greater shift in those who were portrayed 'at work' beginning with $6 \%$ in 2020 and rising to $11 \%$ in 2021 . It is difficult to extrapolate with the examples few in number; however, we may ponder that in line with the motivation to sweep the clutter under the rug, some participants may have felt motivated to portray a more professionally productive visual after 1 year of working from home.

\section{Summary of Image Analysis}

In March 2020, when Jandrić launched the open call for testimonials, teachers, researchers and academics had been freshly thrust into private and domestic spaces that had to morph into work-from-home environments quickly. Although some participants already had an established home office, many had to negotiate caregiving and other elements of their private lives with the technical challenges of working from home, not to mention the emotional turmoil that accompanied life during a pandemic. So early in the transition, the images from this period appear honest and 
raw, revealing a shared experience that was allowed to be messy, complicated and impromptu.

One year later, participants have had time to make adjustments and upgrades to their physical working space while creating new boundaries for their public and private lives. The evaluation of visual data reflects a purposeful curation, not only narrowing the scope of what we are allowed to see, but also indicating a careful selection of items that remain on view. If we must invite the public into our home, does self-preservation motivate us to narrow the boundaries of what should be accessible? As the lines between public and private, indeed between online and offline, increasingly overlap, there appears to be a need to draw visual boundaries. By curating what we allow others to see in the age of Covid-19, perhaps we are exhibiting a form of self-care while respecting the varied circumstances of the viewer.

\section{Discussion}

It is both a privilege and a responsibility to be entrusted with writing the discussion and concluding sections of this article. So much thinking, learning, acting and feeling (Jandrić and Hayes 2020b) have been invested by all individuals who contributed their successive Covid-19 testimonies, in the form of narratives. Now that a sensitive, critically reflexive analysis of these personal accounts, both as textual data and as images have been undertaken, I have found myself reflecting deeply on what has been revealed, what it may mean and what still remains out of sight, or beyond our grasp. The methodology applied in this article is, therefore, understood to be developmental, and further contributions to its visualisation and application are warmly invited.

\section{Postdigital Narratives that are Both Individual and Collective}

When Petar, Aras and Miranda handed the article back to me to work on, I first began instinctively to lightly edit Petar's opening paragraphs, with just a few thoughts of my own, as these occurred. I did not consider whether he would mind that I intruded into a section written by him, because our shared ethos for many years now has resembled a form of participatory and dialogic praxis, enacted through our collaborative writing and editing projects. Sometimes, the voice of one author takes over for a while, and then another joins in and adds a further tone, which they then both explore, and draw conclusions from. Though a different media from making music, there are analogies to be made between collective writing and being part of a band. Different musicians bring different strengths, but the article (or sound) that emerges flows via a form of praxis that brings the different sounds or words together. Though I have not met Aras or Miranda in person, I am already aware that they share an ethos, where critical pedagogy, praxis and dialogue are central to authentic, collaborative research. $\mathrm{I}$, therefore, feel inspired that we can enact our writing relationship in this way, just as if we were sitting together in the same room making music, not located across very different parts of the globe. 
As co-authors, we have developed a 'collective intelligence' (Peters et al. 2021) through the peer production of this article, which is inclusive too of the authors of all of the testimonies. This analysis though does not sit apart from the narratives; it draws data from them, and it also informs what we understand about them, through our findings. These activities provide another dimension too of what Tina Besley refers to as 'postdigital scholarly publishing' (Besley 2021). Whilst many of us who teach and research in education have been used to writing with co-authors across the globe, when the pandemic brought our whole lives online, it shifted and altered all of our activities within our home and workspaces, and not just some of them. The process of writing a narrative of what this felt like, and then photographing what it looked like, was just one way to try to grasp what had altered, and what it might mean, both individually and collectively. I believe these experiences have brought new sensitivities to our online encounters of all kinds, as we have sought to maintain our human social instincts when these can only be expressed through technologies.

The testimonies, as deeply personal narratives, stirred in me a strong emotional connection as I read them, whether I knew each contributor, or not. As authors of these narratives, we have developed intimate ties through the poignancy, pain and pleasure of encountering each other's words and images. I am now keen to learn what a deeper analysis of these, as data, has revealed whilst also continuing to comment on insights that the work done by Aras and Miranda provides into the testimonies, as narratives. As Petar suggested earlier, this section discusses a blend of the two understandings: testimonies as data and testimonies as narratives. Our postdigital methodology of data-narrato-logy is intended to open a shared dialogue about how data and narrative interact, in ways that resemble interactions between theory and practice within the concept of praxis.

\section{What Might Data-Narrato-Logy Look Like?}

One way to visualise such interactions is on an individual level, where the notion of positionality in a postdigital context (Hayes 2021a) helps to keep a focus on the person that the narrative concerns, but reminds us too that their testimony does not stand apart from an interplay of theory and practice in the broader data-narrato-logy context. As such, these mutually constitutive elements intersect (Fig. 5). The datanarrato-logy socio-cultural context surrounding each of us is a complex one, but also a personal and positional domain. Within it, we are both the creators of data and the subjects on whom data is gathered. All forms of writing, images, audio and video that each of us produce are now increasingly treated as data. This is open to manipulation in ways that are seen and unseen, through algorithms, analytics and systems where decisions are often made without our knowledge and power relations are unclear (Fig. 6).

The relatively new field of study called Human Data Interaction (HDI) examines the trend of collecting information about human activities to inform and influence actions and decisions, along with the challenges to analyse this data deluge (Victorelli et al. 2020). As a relatively new field of study, HDI refers to the analysis of the individual and collective decisions we make and the actions we take, whether as users of 
Fig. 6 Data-narrato-logy

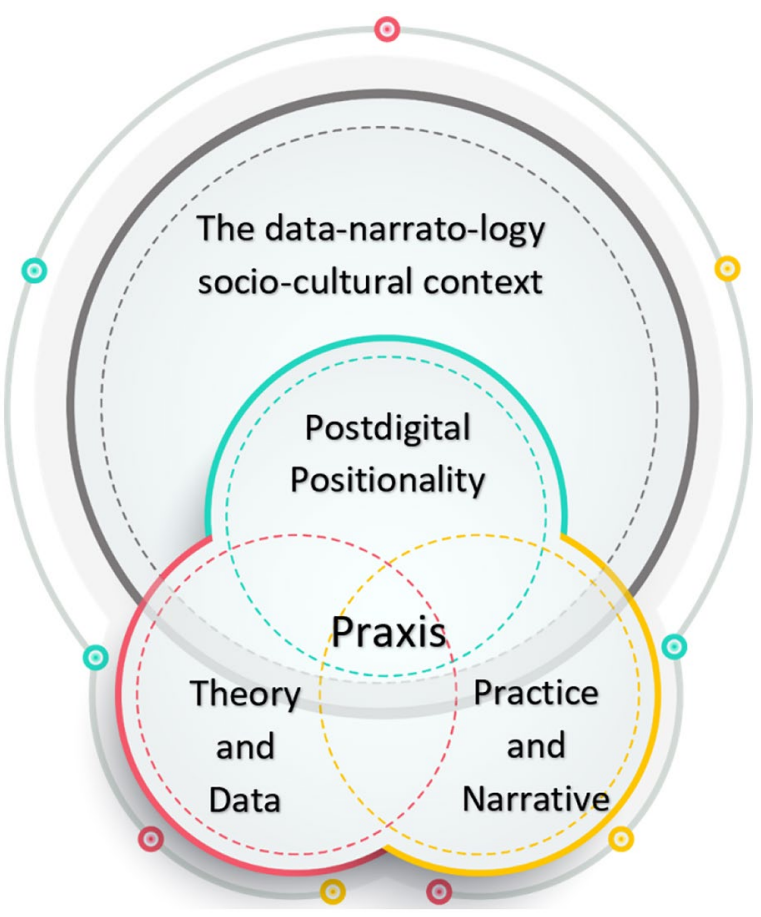

online systems, or as subjects of data collection. Mortier et al. (2014) argue that there are three key aspects to meaningfully interacting with data: legibility, or transparency to help people understand data and processing; agency, which is the power of handling data to give people capacity to control, inform and correct data inferences; negotiability, or the dynamic relationships that emerge regarding data and how each individual's understanding and attitudes change over time, and how they may wish to reevaluate their decisions about their data, as contexts change.

Our discussion of data-narrato-logy brings new dimensions to the topic of HDI, as it concerns the manners in which data and narrative interact and intersect for individuals, drawing comparisons with an interplay between their theory and practice, within the concept of praxis. ${ }^{2}$ We believe this approach is important to disrupt more dominant, political generalisations about Covid-19 experiences made by governing bodies on behalf of others. Thus, our invitation to readers to examine the original testimonies hear their authentic voices, view the original images and try to

\footnotetext{
${ }^{2}$ In a new book soon to be published in the Postdigital Science and Education book series, Human Data Interaction, Disadvantage and Skills in the Community: Enabling Cross-Sector Environments for Postdigital Inclusion, Hayes, Connor, Johnson and Jopling (forthcoming 2022) will facilitate as editors a bottom-up, cross-sector contribution to collective intelligence on HDI and postdigital inclusion, rather than a top-down framework. This will include the contributions that data-narrato-logy approaches bring to this debate, in demonstrating the dynamic flows of data and narrative interactions for individuals, which cannot be captured in static policy documents alone.
} 
move back and forth between the narratives, data and analysis. We freely admit that none of this discussion sits neatly within the frameworks that many policies claim to reside within, but postdigital positionalities are not bounded by neat policy frameworks (Hayes 2021a). They should instead be the resource that informs them. They are hybrid and messy positionalities that require postdigital dialogue to make sense of them (Jandrić et al. 2019).

\section{Data-Narrato-Logy and Textual Analysis}

Whilst the testimonies as narratives had revealed personal, domestic circumstances for each author, the textual analysis of the testimonies as data offered a powerful way to demonstrate how people collectively experienced the concerns of enabling emergency remote online teaching during the first waves of the Covid-19 pandemic. As noted above in the analysis undertaken by Aras, this later shifted focus from crisis management in the mandatory practice of ERT towards more planned and reimagined educational strategies of ODE, as educators moved forward from the uncertainty and anxiety of simply ensuring the sustainability of education at a critical period, to adapting their personal and often shared home workspaces for more permanent acclimatisation. By undertaking the t-SNE analysis of the testimonies as data, the collective professional reactions of these educators are revealed. This demonstrated that despite the sudden closure of the formal public educational infrastructures, teachers at all levels looked beyond the immediate crisis to invent their own strategies to provide for their students as best they could from their diverse home arrangements.

In the text mining analysis of the 2020 testimonies, the three main clusters that emerged from examining the data provide important insights concerning disparities between the circumstances of these educators. Firstly, some people were much better placed than others to respond to the sudden demands of ERT whilst a digital divide, domestic space and personal caring challenges meant that others were considerably disadvantaged. Secondly, the collective emotional and psychological aspects of the crisis were made apparent through the data, reminding us that there are shared consequences, such as depression, stress, loneliness and anxiety, which have arisen and are ongoing. Here, the interplay of praxis between how people now feel, as they enact their practices as educators, and how they, in turn, theorise what they think has changed in relation to this is important. Thirdly, the data brought to light the need to examine ERT as a survival reflex and take time to articulate more on the reasons why we practised it during the pandemic. All of us placed importance on the social empowerment arising through facilitating teaching and learning during a global crisis.

In the three main clusters that emerged from examining the textual data in the 2021 testimonies, the first revealed how teaching had now become a part of daily routines at home. This has prompted a rethink for individuals about the how and where of teaching and the key elements that matter (as authors discussed in their narratives). Considering how this might look, we can imagine that these practices have prompted a return to theory through praxis as shown in Fig. 5. 
As observed by Acevedo et al. (2015), such 'critical reflection, including previously subjugated perspectives' leads to an 'ability to reposition oneself'. Moving from the narratives back to the data, this presents such transformation as a collective experience too, where we are reinventing what the landscape of education now looks like.

The second theme observed concerned the individual and collective focus on hope, as a viral survival mechanism to look beyond the immediate effects of Covid-19, towards the possibilities of the future. The third cluster of data emphasised praxis concerning the hybrid and blended nature of online distance education, where digitally facilitated opportunities require human-centred approaches. Recalling the narratives, their strength was in highlighting the diverse postdigital positionality of students and teachers (Hayes 2021a). So just as educators have engaged with critical pedagogical theory as praxis to inform their new pandemic practices, our analysis of the testimonies as data through data-narrato-logy has informed our deeper reading of the testimonies as narratives in the socio-cultural context.

\section{Data-Narrato-Logy and Image Analysis}

As Petar remarked earlier, text and image, and image and text, are a curious pair. Whilst they do not share a common language, through our methodology of datanarrato-logy, we can bring together points of articulation, where both might contribute to broader knowledge. As Miranda commented earlier, the observation that all knowledge is socially constructed (Jandrić et al. 2021) is valuable to consider when approaching image analysis. The images do not stand alone from their particular socio-cultural context, the text used to describe them or the choices made by the person who photographed them, based on their individual postdigital positionality (Hayes $2021 \mathrm{a}, \mathrm{b})$. This refers to both the postdigital context people inhabit, where the media they use is not separate or other to their human or social life, but it is inclusive too of their positionality.

Positionality theory encapsulates who people identify as in their individual context and their unique experiences that inform this. It is acknowledged that postdigital positionality is not fixed or static. A learner or a teacher's positionality is lived as knowledge, where their 'subjectivity and social positionings play an essential role in the practice of inquiry and knowledge production' (Acevedo et al. 2015: 30). Postdigital positionality enables an observation through praxis, of the complex intersection of these positional identities and experiences, with the virtual, biological and physical spaces we occupy, with systems, media, text, images and power.

The analysis of the images chosen by the authors of the testimonials as a distinct dataset reveals observations that strike a different chord to the textual interpretations. A different view is afforded on the agency involved in the choices of what to include in each image and what to omit. Yet at the same time, taking into account the positionality of those undertaking the analysis is necessary too. We may voice certain critical interpretations, but there are always alternatives that could have been expressed too. It is striking to reflect firstly on the emerging themes in Fig. 5. These capture the key aspects that have surrounded so many of us, as we have worked long 
hours in spaces where at least one computer screen has taken centre stage. It seems that for many of us too, the computer equipment was extended and upgraded as time wore on, along with seating arrangements. I personally sought a new office chair after many months of placing a pillow on my old one.

The image analysis as data offers striking insights into our collective practices of curation of our homeworking spaces. The reduction of physical space that was photographed in the 2021 images, as compared to the 2020 images, seems to chime to some extent with the way in which many people began to switch off their web cams in meetings as the pandemic wore on. The more singular occupation of the workspaces that is noted and the 'putting together' of what people were prepared to show in their images reflect both temporal changes and positional choices.

The observations on the inclusion of physical books, bookshelves, items of art and other artefacts in the images are interesting to speculate on. The shelves of books are a practice that seems to be echoed more widely too, when experts are interviewed virtually in the media and on television news programmes. Exactly who these items are aimed at can only be surmised, along with which of these decisions are conscious or not, on what to include in the frame. What is clear is that there are more choices to be made now, on how we wish to visually present ourselves and our contexts as educators.

Just as our decisions on the static items we display around our workspaces may reveal information on our social standing, there are those we live with to consider too. Before Covid-19, most of us would not have routinely taken a pet, a young child or an elderly or vulnerable relative into the classroom or lecture theatre with us. Yet for many educators with responsibilities at home, these members of our households are now more closely linked with our students and colleagues, via the screens that take us into each other's homes on a daily basis.

All of these practices can give rise to theoretical considerations, such as whether we are inadvertently providing all kinds of data (metadata perhaps) about ourselves that previously remained private. How might this situation alter positionality for both learners and teachers? Given that 'positionality acknowledges complex differentials of power and privilege while simultaneously identifying the value of multiple ways of knowing and being that arise from our multiple identities' (Acevedo et al. 2015: 43), these postdigital, pandemic circumstances require praxis to 'de-center dominant ways of thinking and expose multiple ways of thinking as diverse assets for self-knowing and collective-knowing' (Acevedo et al. 2015: 43).

\section{Concluding Thoughts}

Petar opened the introduction to this article with his ideas on theory as an anti-pandemic practice. Recalling the words of bel hooks, as she described her desperation to comprehend what was happening around her, the notion of theory as a location for healing (hooks 1991: 1) is a powerful one. Petar pointed out though that even the best theory is useless, unless it translates to practice through the centrality of praxis. Individually, praxis enables each of us to make critical connections between our practices and theory, to notice intersections with aspects of our positionality and to work through what 
this could mean, in our postdigital, post-pandemic, socio-cultural contexts. In each of the Covid-19 testimonies collected in 2020 and 2021, the personal narratives reveal praxis and positionality voiced by each contributor from their diverse cultural context. The authors shared their emotions as they revisited their situation 1 year on and many referred to their hopes for what may lay ahead, as Aras discussed earlier in his textual analysis. In her image analysis, Miranda commented on our visual transition from being prepared to show honest, raw views of our impromptu workspaces, to the more guarded, carefully curated views we released 1 year on.

The narratives examined as data have enabled collective experiences and attitudes to be considered through our data-narrato-logy methodology. At the centre of this methodology is a powerful interplay of collective and not just individual praxis. In this article, there is no lone academic expert adviser, individually protecting what he or she writes, or puts on display. No one has shielded their section of the article from interventions by the other co-authors, nor is our analysis socially distancing from the narratives of the authors who wrote their Covid-19 testimonies. Instead, we have enacted a trust and shared praxis that enriches the places where theory and practice intersect, because these are infused with input from our multiple positionalities (just as the testimonies were).

Why is this important at this point in time? Based on the testimonies as both narratives and data, we can conclude that we may have reached something of a turning point now during this pandemic. If, as the analysis has shown, we as individuals have begun to recalibrate the positionalities we are prepared to share, then this may reveal greater agency, but it may also reveal a reluctance to be so open about our vulnerabilities as we were at the start of the pandemic. We need to survive, we need to get on, and therefore praxis may represent a luxury rather than a daily way of being.

Yet the narratives tell us otherwise, they are public textual and visual reminders of what we went through and what we now hope for, and so reading and re-reading them, along with this analysis of the data will help to inform where we would like to get to. Rather than us shutting down our openness to praxis, it has never been more important for us to undertake collective forms of praxis. All of us are subject to manipulation, as humans who interact with data (Mortier et al. 2014). We risk being identified, categorised, datafied and colonised through systems and policies that would also return us to a pre-pandemic state. Yet the spread of Covid-19 has revealed a mass of postdigital human subjectivities from across the globe and a starkly uneven human access to digital devices, skills and services (Hayes 2021b). This is a reminder that in postdigital society, there are also huge numbers of humans and communities who remain pre-digital or semi-digital too (Traxler et al. 2020). In this human, technological and biological collision, praxis offers a route to resist a simple reverting back to what went before, through narratives and data that attest to our diverse postdigital positionalities and what has now changed through the pandemic.

If we persist with forms of postdigital scholarly publication that resist the simplification that comes from the logic of capitalism (Besley 2021) then we have a powerful, collective voice. It is not unlike that of a band that draws different strengths from its musicians. Once the sound they make is released, it has a collective power 
that is not just attributed to sole artists but draws on the diverse strengths of all who contributed. We therefore acknowledge now the contributions of all of the authors of the Covid-19 testimonies as narratives and thank them for what we have been able to draw from these as data. Our discussion and conclusion have blended the two understandings to demonstrate why we think this approach is important, to disrupt more dominant, political generalisations about Covid-19 experiences. We consider ourselves to be a collaborative group of authors with individual positionalities in postdigital society, but collectively, we acknowledge that our testimonies do not stand apart from an interplay of theory and practice in the broader data-narrato-logy context. As such, these mutually constitutive accounts offer a much larger, powerful commentary, on the position of educators across the globe during this pandemic.

\section{References}

Acevedo, S. M., Aho, M., Cela, E., Chao, J. C., Garcia-Gonzales, I., MacLeod, A., Moutray, C., \& Olague, C. (2015). Positionality as Knowledge: From Pedagogy to Praxis. Integral Review: A Transdisciplinary \& Transcultural Journal for New Thought, Research, \& Praxis, 11(1), 28-46.

Arndt, S., Asher, G., Knox, J., Ford, D. R., Hayes, S., Lăzăroiu, G., Jackson, L., Mañero Contreras, J., Buchanan, R., D’Olimpio, L., Smith, M., Suoranta, J., Pyyhtinen, O., Ryberg, T., Davidsen, J., Steketee, A., Mihăilă, R., Stewart, G., Dawson, M., Sinclair, C., \& Peters, M. A. (2019). Between the blabbering noise of individuals or the silent dialogue of many: a collective response to 'Postdigital Science and Education' (Jandrić et al. 2018). Postdigital Science and Education, 1(2), 446474. https://doi.org/10.1007/s42438-019-00037-y.

Berger, J. (1972). Ways of Seeing [Documentary Film]. London: BBC. https://www.ways-of-seeing.com/. Accessed 15 July 2021.

Besley, T. (2021). Postdigital Scholarly Publishing. Postdigital Science and Education. https://doi.org/10. 1007/s42438-021-00248-2.

Bozkurt, A., \& Sharma, R. C. (2020a). Emergency remote teaching in a time of global crisis due to CoronaVirus pandemic. Asian Journal of Distance Education, 15(1), i-vi. https://doi.org/10.5281/ zenodo.3778083.

Bozkurt, A., \& Sharma, R. C. (2020b). Education in normal, new normal, and next normal: Observations from the past, insights from the present and projections for the future. Asian Journal of Distance Education, 15(2), i-x. https://doi.org/10.5281/zenodo.4362664.

Bozkurt, A., \& Sharma, R. C. (2021). On the verge of a new renaissance: Care and empathy oriented, human-centered pandemic pedagogy. Asian Journal of Distance Education, 16(1), i-vii. https://doi. org/10.5281/zenodo.5070496.

Bozkurt, A., Jung, I., Xiao, J., Vladimirschi, V., Schuwer, R., Egorov, G., ... \& Paskevicius, M. (2020). A global outlook to the interruption of education due to COVID-19 pandemic: Navigating in a time of uncertainty and crisis. Asian Journal of Distance Education, 15(1), 1-126. https://doi.org/10.5281/ zenodo. 3878572 .

Cahapay, M. B. (2020). A reconceptualization of learning space as schools reopen amid and after COVID-19 pandemic. Asian Journal of Distance Education, 15(1), 269-276. https://doi.org/10. 5281/zenodo.3892969.

Costello, E., Brown, M., Donlon, E., \& Girme, P. (2020). 'The Pandemic Will Not be on Zoom': A Retrospective from the Year 2050. Postdigital Science and Education, 2(3), 619-627. https://doi.org/10. 1007/s42438-020-00150-3.

Darling-Hammond, L., \& Hyler, M. E. (2020). Preparing educators for the time of COVID... and beyond. European Journal of Teacher Education, 43(4), 457-465. https://doi.org/10.1080/02619768. 2020.1816961.

Darwin, C. (1859). On the origin of species by means of natural selection or the preservation of favoured races in the struggle for life. London: J. Murray.

Davey, N. (2005). The Hermeneutics of Seeing. In D. I. Heywood \& B. Sandywell (Ed.), Interpreting Visual Culture: Explorations in the Hermeneutics of Vision (pp. 3-19). New York: Routledge. 
Dwivedi, Y. K., Hughes, D. L., Coombs, C., Constantiou, I., Duan, Y., Edwards, J. S., ... \& Upadhyay, N. (2020). Impact of COVID-19 pandemic on information management research and practice: Transforming education, work and life. International Journal of Information Management, 55, 102211. https://doi.org/10.1016/j.ijinfomgt.2020.102211.

Eddles-Hirsch, K. (2015). Phenomenology and educational research. International Journal of Advanced Research, 3(8), 251-260.

Elmer, T., Mepham, K., \& Stadtfeld, C. (2020). Students under lockdown: Comparisons of students' social networks and mental health before and during the COVID-19 crisis in Switzerland. Plos One, 15(7), e0236337. https://doi.org/10.1371/journal.pone.0236337.

Fawns, T., Aitken, G., \& Jones, D. (2020). Ecological teaching evaluation vs the datafication of quality: Understanding education with, and around, data. Postdigital Science and Education, 3(1), 65-82. https://doi.org/10.1007/s42438-020-00109-4.

Fayyad, U., Grinstein, G. G., \& Wierse, A. (Eds.). (2002). Information visualization in data mining and knowledge discovery. San Francisco: Morgan Kaufmann.

Feldman, R., \& Sanger, J. (2007). The text mining handbook: Advanced approaches in analyzing unstructured data. New York: Cambridge University Press.

Flood, A. (2010). Understanding phenomenology: Anne Flood looks at the theory and methods involved in phenomenological research. Nurse Researcher, 17(2), 7-15. https://doi.org/10.7748/nr2010.01.17.2.7.c7457.

Gallagher, M. W., Smith, L. J., Richardson, A. L., D’Souza, J. M., \& Long, L. J. (2021). Examining the longitudinal effects and potential mechanisms of hope on COVID-19 stress, anxiety, and well-being. Cognitive Behaviour Therapy, 50(3), 234-245. https://doi.org/10.1080/16506073.2021.1877341.

Hayes, S. (2021a). Postdigital Positionality: developing powerful inclusive narratives for learning, teaching, research and policy in Higher Education. Leiden: Brill.

Hayes, S. (2021b). The Value of Postdigital Humans as Objects, or Subjects, in McDonaldised Society. In M. Savin-Baden (Ed.), Postdigital Humans: Transitions, Transformations and Transcendence (pp. 71-87). Cham: Springer. https://doi.org/10.1007/978-3-030-65592-1_5.

Hayes, S., Connor, S., Johnson, M., \& Jopling, M. (forthcoming 2022). Human Data Interaction, Disadvantage and Skills in the Community: Enabling Cross-Sector Environments for Postdigital Inclusion. Cham: Springer.

Heidegger, M. (1982). On the way to language. San Francisco, CA: Harper \& Row.

Hodges, C., Moore, S., Lockee, B., Trust, T., \& Bond, A. (2020). The difference between emergency remote teaching and online learning. Educause Review, 27 March. https://er.educause.edu/articles/2020/3/thedifference-between-emergency-remote-teaching-and-online-learning. Accessed 10 June 2021.

hooks, b. (1991). Theory as Liberatory Practice. Yale Journal of Law \& Feminism, 4(1), 1-12.

Jandrić, P. (2019). We-Think, We-Learn, We-Act: the Trialectic of Postdigital Collective Intelligence. Postdigital Science and Education, 1(2), 257-279. https://doi.org/10.1007/s42438-019-00055-w.

Jandrić, P. (2020a). The Day After Covid-19. Postdigital Science and Education, 3(2), 531-537. https:// doi.org/10.1007/s42438-020-00195-4.

Jandrić, P. (2020b). The Postdigital Challenge of Pandemic Education. Journal of Contemporary Educational Studies, 71(4), 176-189.

Jandrić, P. (2020c). A Message to You, Rudy: Hear Reason, Or Nature Will Make You Feel Her. Knowledge Cultures, 8(2), 23-28. https://doi.org/10.22381/kc8220204.

Jandrić, P. (2020d). Corona-Party at the Ruins of an Earthquake. Social Epistemology Review and Reply Collective, 9(5), 34-39.

Jandrić, P., \& Hayes, S. (2020a). Writing the History of the Present, 3(2), 1062-1068. Postdigital Science and Education. https://doi.org/10.1007/s42438-020-00168-7.

Jandrić, P., \& Hayes, S. (2020b). Postdigital We-Learn. Studies in Philosophy of Education, 39(3), 285297. https://doi.org/10.1007/s11217-020-09711-2.

Jandrić, P., Hayes, D., Levinson, P., Lisberg Christensen, L., Lukoko, H. O., Kihwele, J. E., Brown, J. B., Reitz, C., Mozelius, P., Nejad, H. G., Fuentes Martinez, A., Arantes, J. A., Jackson, L., Gustafsson, U., Abegglen, S., Burns, T., Sinfield, S., Hogan, M., Kishore, P., Carr, P. R., Batarelo Kokić, I., Prinsloo, P., Grauslund, D., Steketee, A., Achieng-Evensen, C., Komolafe, B. F., Suoranta, J., Hood, N., Tesar, M., Rose, J., Humble, N., Kirylo, J. D., Mañero, J., Monzó, L. D., Lodahl, M., Jaldemark, J., Bridges, S. M., Sharma, N., Davidsen, J., Ozoliņ̌̌, J., Bryant, P., Escaño, C., Irwin, J., Kaur, K., Pfohl, S., Stockbridge, K., Ryberg, T., Pyyhtinen, O., SooHoo, S., Hazzan, M. K., Wright, J., Hollings, S., Arndt, S., Gibbons, A., Urvashi, S., Forster, D. J., Truelove, I., Mayo, P., Rikowski, G., Stewart, P. A., Jopling, M., Stewart, G. T., Buchanan, R., Devine, N., Shukla, R., Novak, R., Mallya, M., Biličić, E., Sturm, S., Sattarzadeh, S. D., Philip, A. P., Redder, B., White, E. J., Ford, 
D. R., Allen, Q., Mukherjee, M., \& Hayes, S. (2021). Teaching in the Age of Covid-19-1 Year Later. Postdigital Science and Education. https://doi.org/10.1007/s42438-021-00243-7.

Jandrić, P., Hayes, D., Truelove, I., Levinson, P., Mayo, P., Ryberg, T., Monzó, L.D., Allen, Q., Stewart, P.A., Carr, P.R., Jackson, L., Bridges, S., Escaño, C., Grauslund, D., Mañero, J., Lukoko, H.O., Bryant, P., Fuentes Martinez, A., Gibbons, A., Sturm, S., Rose, J., Chuma, M.M., Biličić, E., Pfohl, S., Gustafsson, U., Arantes, J.A., Ford, D.R., Kihwele, J.E., Mozelius, P., Suoranta, J., Jurjević, L., Jurčević, M., Steketee, A., Irwin, J., White, E.J., Davidsen, J., Jaldemark, J., Abegglen, S., Burns, T., Sinfield, S., Kirylo, J.D., Batarelo Kokić, I., Stewart, G.T., Rikowski, G., Lisberg Christensen, L., Arndt, S., Pyyhtinen, O., Reitz, C., Lodahl, M., Humble, N., Buchanan, R., Forster, D.J., Kishore, P., Ozoliņ̌s, J., Sharma, N., Urvashi, S., Nejad, H.G., Hood, N., Tesar, M., Wang, Y., Wright, J., Brown, J.B., Prinsloo, P., Kaur, K., Mukherjee, M., Novak, R., Shukla, R., Hollings, S., Konnerup, U., Mallya, M., Olorundare, A., Achieng-Evensen, C., Philip, A.P., Hazzan, M.K., Stockbridge, K., Komolafe, B.F., Bolanle, O.F., Hogan, M., Redder, B., Sattarzadeh, S.D., Jopling, M., SooHoo, S., Devine, N., \& Hayes, S. (2020). Teaching in The Age of Covid-19. Postdigital Science and Education, 2(3), 1069-1230. https://doi.org/10.1007/s42438-020-00169-6.

Jandrić, P., Ryberg, T., Knox, J., Lacković, N., Hayes, S., Suoranta, J., Smith, M.; Steketee, A., Peters, M. A., McLaren, P., Ford, D. R., Asher, G., McGregor, C., Stewart, G., Williamson, B., \& Gibbons, A. (2019). Postdigital Dialogue. Postdigital Science and Education, 1(1), 163-189. https://doi.org/10. 1007/s42438-018-0011-x.

Karakaya, K. (2021). Design considerations in emergency remote teaching during the COVID-19 pandemic: A human-centered approach. Educational Technology Research and Development, 69(1), 295-299. https://doi.org/10.1007/s11423-020-09884-0.

Loose, C. C., \& Ryan, M. G. (2020). Cultivating teachers when the school doors are shut: Two teachereducators reflect on supervision, instruction, change and opportunity during the Covid-19 Pandemic. Frontiers in Education, 5, 582561. https://doi.org/10.3389/feduc.2020.582561.

Milan, S. (Ed.). (2021). COVID-19 from the margins: Pandemic invisibilities, policies and resistance in the datafied society. Amsterdam: Institute of Network Cultures.

Mishra, L., Gupta, T., \& Shree, A. (2020). Online teaching-learning in higher education during lockdown period of COVID-19 pandemic. International Journal of Educational Research Open, 1, 100012. https://doi.org/10.1016/j.ijedro.2020.100012.

Moore, M. G. (1993). Theory of transactional distance. In D. Keegan (Ed.), Theoretical principles of distance education (pp. 22-38). London: Routledge.

Moore, M. G., \& Kearsley, G. (2012). Distance education: A systems view of online learning. Belmont: Cengage.

Mortier, R., Haddadi, H., Henderson, T., McAuley, D., \& Crowcroft, J. (2014). Human-data interaction: The human face of the data-driven society. SSRN. https://doi.org/10.2139/ssrn.2508051.

Nietzsche, F. (1986). Human, all too human: A book for free spirits. Cambridge University Press.

Patton, M. Q. (2015). Qualitative research and evaluation methods. 4th Ed. Thousand Oaks, CA: Sage.

Pelletier, K., Brown, M., Brooks, D. C., McCormack, M., Reeves, J., Arbino, N., Bozkurt, A., Crawford, S., Czerniewicz, L., Gibson, R., Linder, K., Mason, J., \& Mondelli, V. (2021). 2021 EDUCAUSE Horizon Report Teaching and Learning Edition. EDUCAUSE. https://www.learntechlib.org/p/ 219489/. Accessed 15 July 2021.

Peters, M. A., Rizvi, F., McCulloch, G., Gibbs, P., Gorur, R., Hong, M., Hwang, Y., Zipin, L., Brennan, M., Robertson, S., Quay, J., Malbon, J., Taglietti, D., Barnett, R., Chengbing, W., McLaren, P., Apple, R., Papastephanou, M., Burbules, N., Jackson, L., Jalote, P., Kalantzis, M:, Cope, B., Fataar, A., Conroy, J., Misiaszek, G., Biesta, G., Jandrić, P., Choo, S., Apple, M., Stone, L., Tierney, R., Tesar, M:, Besley, T., \& Misiaszek, L. (2020): Reimagining the new pedagogical possibilities for universities post-Covid-19. Educational Philosophy and Theory. https://doi.org/10.1080/00131857.2020.1777655.

Peters, M. A., Besley, T., Tesar, M., Jackson, L., Jandrić, P., Arndt, S., \& Sturm, S. (2021). The Methodology and Philosophy of Collective Writing. Abingdon and New York: Routledge.

Rudnick, A. (2020). Social, psychological, and philosophical reflections on pandemics and beyond. Societies, 10(2). https://doi.org/10.3390/soc10020042.

Sikora, J., Evans, M. D. R., \& Kelley, J. (2019). Scholarly culture: How books in adolescence enhance adult literacy, numeracy and technology skills in 31 societies. Social Science Research, 77, 1-15. https://doi.org/10.1016/j.ssresearch.2018.10.003.

Smith, A. E., \& Humphreys, M. S. (2006). Evaluation of unsupervised semantic mapping of natural language with Leximancer concept mapping. Behavior Research Methods, 38(2), 262-279. https://doi. org/10.3758/BF03192778.

Sontag, S. (1990). On photography. New York: Anchor Books. 
Spencer, H. (1908). The filiation of ideas. In D. Duncan (Ed.), The Life and Letters of Herbert Spencer. London: Williams and Norgate.

Thurmond, V. A. (2001). The point of triangulation. Journal of Nursing Scholarship, 33(3), 253-258. https://doi.org/10.1111/j.1547-5069.2001.00253.x

Time. (2021). The great reset. https://time.com/collection/great-reset/. Accessed 15 July 2021.

Traxler, J., Connor, S., Hayes, S., \& Jandrić, P. (2021). Futures Studies, Mobilities, and the Postdigital Condition: Contention or Complement. Postdigital Science and Education. https://doi.org/10.1007/ s42438-021-00245-5.

Traxler, J., Smith, M., Scott, H., \& Hayes, S. (2020). Learning through the crisis: Helping decision-makers around the world use digital technology to combat the educational challenges produced by the current COVID-19 pandemic. Wolverhampton: EdTech Hub. https://wlv.openrepository.com/handle/2436/ 623949. Accessed 10 June 2021.

UNESCO. (2020). Global Education Coalition. https://en.unesco.org/covid19/educationresponse/globalcoalition. Accessed 15 July 2021.

van der Maaten, L., \& Hinton, G. (2008). Visualizing data using t-SNE. Journal of Machine Learning Research, 9, 2579-2605.

Veletsianos, G., \& Houlden, S. (2020). Radical flexibility and relationality as responses to education in times of crisis. Postdigital Science and Education, 2(3), 849-862. https://doi.org/10.1007/ 2Fs42438-020-00196-3.

Victorelli, E. Z., Dos Reis, J. C., Hornung, H., \& Prado, A. B. (2020). Understanding human-data interaction: Literature review and recommendations for design. International Journal of Human-Computer Studies, 134, 13-32. https://doi.org/10.1016/j.ijhcs.2019.09.004.

World Health Organisation. (2021). Coronavirus disease (COVID-19) outbreak. https://www.who.int/ emergencies/diseases/novel-coronavirus-2019. Accessed 10 June 2021.

Xiao, J. (2021a). From equality to equity to justice: Should online education be the new normal in education? In A. Bozkurt (Ed.), Handbook of research on emerging pedagogies for the future of education: Trauma-informed, care, and pandemic pedagogy (pp. 1-15). Hershey, PA: IGI Global. http:// doi:https://doi.org/10.4018/978-1-7998-7275-7.ch001.

Xiao, J. (2021b). Decoding new normal in education for the post-COVID-19 world: Beyond the digital solution. Asian Journal of Distance Education, 16(1), 141-155. https://doi.org/10.5281/zenodo.4818369.

Yusoff, M. S. B., Hadie, S. N. H., Mohamad, I., Draman, N., Al-Aarifin, I. M., Rahman, W. F. W. A., ... \& Yaacob, N. A. (2020). Sustainable medical teaching and learning during the COVID-19 pandemic: Surviving the new normal. The Malaysian Journal of Medical Sciences, 27(3), 137-142. https://doi. org/10.21315/2Fmjms2020.27.3.14.

Zhang, W., Wang, Y., Yang, L., \& Wang, C. (2020). Suspending classes without stopping learning: China's education emergency management policy in the COVID-19 outbreak. Journal of Risk and Financial Management, 13(55), 1-6. https://doi.org/10.3390/jrfm13030055.

\section{Authors and Affiliations}

\section{Petar Jandrić ${ }^{1,4} \cdot$ Aras Bozkurt $^{2}$ (D) Miranda McKee $^{3} \cdot$ Sarah Hayes $^{4}$ (ID}

Aras Bozkurt

arasbozkurt@gmail.com

Miranda McKee

mmckee6@lakeheadu.ca

Sarah Hayes

sarah.hayes@wlv.ac.uk

1 Zagreb University of Applied Sciences, Zagreb, Croatia

2 Anadolu University, Eskişehir, Turkey

3 Lakehead University, Orillia, Canada

4 University of Wolverhampton, Wolverhampton, UK 